\title{
Urban Aboriginal and Torres Strait Islander children's exposure to stressful events: a cross-sectional study
}

\section{Deborah A Askew PhD, MHIthSc GradDipNutr\&Diet, Senior Lecturer ${ }^{1}$ and Research Director ${ }^{2}$ \\ Philip J Schluter BSc(Hons), MSc, PhD, \\ Professor of Population \\ Health and Head of School, ${ }^{3}$ and Honorary Professor of Biostatistics}

Geoffrey K P Spurling MB BS, FRACGP, MPH Senior Lecturer ${ }^{1}$ and General Practitioner

Chelsea J R Bond

BAppSci(Hons), PhD Senior Lecturer

Alex D H Brown PhD, FRACP Professor and Indigenous Health Theme Leader

1 Discipline of Genera

Practice, University of Queensland Brisbane $\mathrm{QLD}$

2 Inala Indigenous Health Service, Queensland Health, Brisbane, QLD.

3 School of Health

Sciences, University of Canterbury, Christchurch, New Zealand.

4 School of Nursin and Midwifer

University of Queensland Brisbane, QLD.

5 Aboriginal and Torres Strait Islander Studies Unit, University of Queensland Brisbane, QLD.

6 South Australian

Health and Medic Research Institute, Adelaide, SA.

d.askew@uq.edu.au

MJA 2013; 199: 42-45 doi: 10.5694/mjal2.11716

Editorial p 14 dverse life events and chronic stressors experienced during early childhood can negatively affect development. ${ }^{1,2}$ While some exposure to stressful events can foster resilience, ${ }^{3}$ exposure to strong, frequent or prolonged stressors in childhood can result in dysregulation of physiological stress response systems, ${ }^{2,4}$ which can negatively affect the development of social and emotional wellbeing, behaviour, literacy, and physical and mental health. ${ }^{2,45}$ With the strong association between racial inequalities in health and chronic stress, ${ }^{6,7}$ the inequalities experienced by Aboriginal and Torres Strait Islander peoples compared with non-Indigenous Australians need to be considered in this context.

Aboriginal and Torres Strait Islander peoples experience higher rates of stressful events than the general population, which can, in part, be attributed to the lasting impact of colonisation, intergenerational trauma and ongoing experiences of disadvantage and exclusion. $^{7-9}$ The 2010 General Social Survey found that $61 \%$ of Australians aged $\geqslant 18$ years had experienced at least one stressful event during the preceding year. ${ }^{10}$ In comparison, the 2008 National Aboriginal and Torres Strait Islander Social Survey (NATSISS) found that $77 \%$ of Indigenous adults and $65 \%$ of Indigenous children aged 4-14 years had experienced at least one stressful event, ${ }^{11}$ and the Western Australian Aboriginal Child Health Survey (WAACHS) found that 71\% of children had experienced at least three significant stressors. ${ }^{12}$ All three surveys used a checklist of negative life events to identify stressful events experienced in the previous year.

Indigenous children living in urban areas experience higher rates of stressful events than their counterparts in rural or remote areas. ${ }^{11,12}$ However, there is little research investigating

Abstract

Objectives: To determine the frequency and types of stressful events experienced by urban Aboriginal and Torres Strait Islander children, and to explore the relationship between these experiences and the children's physical health and parental concerns about their behaviour and learning ability.

Design, setting and participants: Cross-sectional study of Aboriginal and Torres Strait Islander children aged $\leqslant 14$ years presenting to an urban Indigenous primary health care service in Brisbane for annual child health checks between March 2007 and March 2010.

Main outcome measures: Parental or carer report of stressful events ever occurring in the family that may have affected the child.

Results: Of 344 participating children, 175 (51\%) had experienced at least one stressful event. Reported events included the death of a family member or close friend $(40 ; 23 \%)$, parental divorce or separation (28; $16 \%)$, witness to violence or abuse $(20 ; 11 \%)$, or incarceration of a family member $(7 ; 4 \%)$. These children were more likely to have parents or carers concerned about their behaviour $(P<0.001)$ and to have a history of ear $(P<0.001)$ or skin $(P=0.003)$ infections.

Conclusions: Children who had experienced stressful events had poorer physical health and more parental concern about behavioural issues than those who had not. Parental disclosure in the primary health care setting of stressful events that have affected the child necessitates appropriate medical, psychological or social interventions to ameliorate both the immediate and potential lifelong negative impact. However, treating the impact of stressful events is insufficient without dealing with the broader political and societal issues that result in a clustering of stressful events in the Aboriginal and Torres Strait Islander population.

their health status, despite the majority of Indigenous Australians living in urban settings and the different social and cultural milieus associated with these communities. ${ }^{13,14}$ We aimed to determine the frequency and types of stressful events experienced by urban Aboriginal and Torres Strait Islander children, and to explore the relationship between these experiences and the children's physical health and parental concerns about their behaviour and learning ability.

\section{Methods}

This cross-sectional study used data collected during annual child health checks (CHCs) at the Inala Indigenous Health Service (IIHS) in Brisbane. The $\mathrm{CHC}$ is a comprehensive health assessment that aims to increase access to preventive health care. ${ }^{15}$ The IIHS, a Queensland Government general practice service, ${ }^{16}$ had 867 children listed as regular patients at the time of the study.

We recruited a consecutive sample of children aged $\leqslant 14$ years presenting for CHCs between March 2007 and March 2010, whose parents or carers consented to the $\mathrm{CHC}$ information being used for research. Most children had one $\mathrm{CHC}$ during the study period; for those who had two or more $\mathrm{CHCs}$, only data from the first visit were included.

Parents or carers were asked if any stressful events had occurred in the family that may have affected the child. Responses to this question were not limited by a time frame of when the events occurred or by use of a checklist of negative life events. 
Parents or carers were also asked if the child had a history of chest, ear or skin infections, or injuries or burns, and if they had concerns about the child's behaviour or learning ability. For school-aged children, parents or carers were asked to compare the child's school grades to average. The child's weight and height were measured and body mass index $\left(\mathrm{kg} / \mathrm{m}^{2}\right)$ was calculated. Family groupings of children were identified post-hoc by matching children's surnames, addresses, known siblings, household size, presentation on the same day for a $\mathrm{CHC}$, or the same stressful events being recorded.

We categorised the reported stressful events and calculated the proportion of children affected by each category of stressor. Using Stata, version 10.0 (StataCorp), we tested for relationships between reported stressful events and the independent variables using binary generalised estimating equation (GEE) methods, nesting children within families, employing exchangeable correlation structures and robust estimators of variance. A two-sided significance level $(\alpha)$ of $5 \%$ was used to define statistical significance.

Ethics approval was obtained from the University of Queensland's Behavioural and Social Sciences Ethical Review Committee and the Metro South Human Research Ethics Committee. The Inala Elders Aboriginal and Torres Strait Islander Corporation supported the project, and results were disseminated back to the Inala Aboriginal and Torres Strait Islander community.

\section{Results}

Of the 541 children having CHCs in the study period, parental or carer consent to participate in research was gained for $432(80 \%)$, and 344 (64\%) were eligible for this study. These 344 children had a mean age of 7.3 years and were from 247 families. Most children were Aboriginal (312; 91\%) and lived with at least one parent (286; 83\%) (Box 1). Household size ranged from two to 11 usual members, with a median of five. No sibling was identified for 177 participants (51\%); 50 participants (15\%) had one

1 Individual and familial characteristics of children having child health checks at Inala Indigenous Health Service, March 2007 - March 2010, by experience of stressful events

\begin{tabular}{|c|c|c|c|c|}
\hline \multirow[b]{2}{*}{ Characteristic } & \multirow[b]{2}{*}{ Overall $(n=344)$} & \multicolumn{2}{|c|}{ At least one stressful event } & \multirow[b]{2}{*}{ P* } \\
\hline & & Yes $(n=175)$ & No $(n=169)$ & \\
\hline Sex & & & & 0.40 \\
\hline Male & $180(52 \%)$ & $94(54 \%)$ & $86(51 \%)$ & \\
\hline Female & $164(48 \%)$ & $81(46 \%)$ & $83(49 \%)$ & \\
\hline Age (years) & & & & 0.45 \\
\hline$\leqslant 4$ & $107(31 \%)$ & $52(30 \%)$ & $55(33 \%)$ & \\
\hline $5-9$ & $142(41 \%)$ & $78(45 \%)$ & $64(38 \%)$ & \\
\hline $10-14$ & $95(28 \%)$ & $45(26 \%)$ & $50(30 \%)$ & \\
\hline Ethnicity & & & & 0.96 \\
\hline Aboriginal & $312(91 \%)$ & $157(90 \%)$ & $155(92 \%)$ & \\
\hline Torres Strait Islander & $7(2 \%)$ & $5(3 \%)$ & $2(1 \%)$ & \\
\hline Both Aboriginal and Torres Strait Islander & $25(7 \%)$ & $13(7 \%)$ & $12(7 \%)$ & \\
\hline Main carer with whom the child lives ${ }^{\dagger}$ & & & & 0.07 \\
\hline Parent(s) & $286(84 \%)$ & $137(80 \%)$ & $149(89 \%)$ & \\
\hline Grandparent(s) & $15(4 \%)$ & $8(5 \%)$ & $7(4 \%)$ & \\
\hline Other relative(s) & $20(6 \%)$ & $15(9 \%)$ & $5(3 \%)$ & \\
\hline Friend(s) & $1(0.3 \%)$ & $1(1 \%)$ & 0 & \\
\hline In care & $17(5 \%)$ & $11(6 \%)$ & $6(4 \%)$ & \\
\hline Single-parent household ${ }^{\ddagger}$ & & & & 0.10 \\
\hline Yes & $151(44 \%)$ & $87(50 \%)$ & $64(38 \%)$ & \\
\hline No & $192(56 \%)$ & $87(50 \%)$ & $105(62 \%)$ & \\
\hline Employment status of parent(s)/carer(s) ${ }^{\ddagger}$ & & & & 0.10 \\
\hline Employed & $121(35 \%)$ & $49(28 \%)$ & $72(43 \%)$ & \\
\hline Unemployed & $222(65 \%)$ & $125(72 \%)$ & $97(57 \%)$ & \\
\hline Teenage parent $(\mathrm{s})^{\ddagger}$ & & & & 0.23 \\
\hline Yes & $14(4 \%)$ & $9(5 \%)$ & $5(3 \%)$ & \\
\hline No & $329(96 \%)$ & $165(95 \%)$ & $164(97 \%)$ & \\
\hline
\end{tabular}

* Calculated using binary generalised estimating equation methods, clustering children within their families. $\dagger$ Three observations missing from the group exposed to stressful events, and two from the group not exposed. $¥$ One observation missing from the group exposed to stressful events.

\section{Frequency of stressful events reported by parents or carers during child health} checks for children who had experienced at least one stressful event $(n=175)$

Stressful event category

Conflict in the family

Death of family member or close friend

Parental divorce or separation

Housing issues (including overcrowding and housing insecurity)

Lack of emotional support from parents

Serious illness in the family

Witness to violence or abuse (including domestic violence)

Experienced abuse or violent crime (including domestic violence)

Living away from parents, with other family members

In foster care

Alcohol or drug-related problem in the family

Problems at school

New to community

Family member in prison

Other
No. (\%) of children

$42(24 \%)$

$40(23 \%)$

$28(16 \%)$

$27(15 \%)$

$26(15 \%)$

$23(13 \%)$

$20(11 \%)$

$18(10 \%)$

$17(10 \%)$

$16(9 \%)$

$13(7 \%)$

$11(6 \%)$

$10(6 \%)$

$7(4 \%)$

$11(6 \%)$ sibling, 13 (4\%) had two siblings, and seven (2\%) had three siblings.

Of the 344 participants, 175 (51\%) had experienced stressful events. There were no significant differences in the reported exposure to stressful events between sexes or age groups. Children from single-parent households or with teenage or unemployed parents were also no more likely to have been affected by stressful events than their counterparts (Box 1). 
3 Parental concerns about children's behaviour and learning ability and physical health of children, by experience of stressful events

\begin{tabular}{|c|c|c|c|c|}
\hline \multirow[b]{2}{*}{ Variable } & \multirow[b]{2}{*}{ Overall } & \multicolumn{2}{|c|}{ At least one stressful event } & \multirow[b]{2}{*}{$P *$} \\
\hline & & Yes & No & \\
\hline \multicolumn{5}{|l|}{ Behaviour and learning ability } \\
\hline Parents or carers concerned about behaviour ${ }^{\dagger}$ & 234 & 124 & 110 & $<0.001$ \\
\hline Yes & $69(29 \%)$ & $50(40 \%)$ & $19(17 \%)$ & \\
\hline No & $165(71 \%)$ & $74(60 \%)$ & $91(83 \%)$ & \\
\hline Parents or carers concerned about learning ${ }^{\dagger}$ & 236 & 126 & 110 & 0.10 \\
\hline Yes & $75(32 \%)$ & $47(37 \%)$ & $28(25 \%)$ & \\
\hline No & $161(68 \%)$ & $79(63 \%)$ & $82(75 \%)$ & \\
\hline School grades on report card ${ }^{\dagger \ddagger}$ & 193 & 95 & 98 & 0.19 \\
\hline Below average & $36(19 \%)$ & $24(25 \%)$ & $12(12 \%)$ & \\
\hline Average or above average & $157(81 \%)$ & $71(75 \%)$ & $86(88 \%)$ & \\
\hline \multicolumn{5}{|l|}{ Physical health } \\
\hline Body mass index (BMI) category ${ }^{\dagger}$ & 292 & 151 & 141 & 0.62 \\
\hline Overweight or obese $\left(\mathrm{BMI}>25 \mathrm{~kg} / \mathrm{m}^{2}\right)$ & $75(26 \%)$ & $37(25 \%)$ & $38(27 \%)$ & \\
\hline Normal or underweight $\left(\mathrm{BMI} \leqslant 25 \mathrm{~kg} / \mathrm{m}^{2}\right.$ ) & $217(74 \%)$ & $114(75 \%)$ & $103(73 \%)$ & \\
\hline History of chest infections ${ }^{\dagger}$ & 308 & 156 & 152 & 0.10 \\
\hline Yes & $33(11 \%)$ & $23(15 \%)$ & $10(7 \%)$ & \\
\hline No & $275(89 \%)$ & $133(85 \%)$ & $142(93 \%)$ & \\
\hline History of ear infections ${ }^{\dagger}$ & 313 & 160 & 153 & $<0.001$ \\
\hline Yes & $87(28 \%)$ & $58(36 \%)$ & $29(19 \%)$ & \\
\hline No & $226(72 \%)$ & $102(64 \%)$ & $124(81 \%)$ & \\
\hline History of skin infections ${ }^{\dagger}$ & 308 & 158 & 150 & 0.003 \\
\hline Yes & $67(22 \%)$ & $48(30 \%)$ & $19(13 \%)$ & \\
\hline No & $241(78 \%)$ & $110(70 \%)$ & $131(87 \%)$ & \\
\hline History of burns or injuries ${ }^{\dagger}$ & 306 & 153 & 153 & 0.51 \\
\hline Yes & $42(14 \%)$ & $25(16 \%)$ & $17(11 \%)$ & \\
\hline No & $264(86 \%)$ & $128(84 \%)$ & $136(89 \%)$ & \\
\hline
\end{tabular}

Categories of reported stressful events are shown in Box 2. Of the 175 children who had ever experienced stressful events, $42(24 \%)$ had been affected by conflict in the family, 40 $(23 \%)$ by the death of a family member or close friend, and $27(15 \%)$ by housing issues, including overcrowding or housing insecurity. Violence or abuse, including domestic violence, had been witnessed by $20(11 \%)$ and personally experienced by 18 children (10\%).

Children affected by stressful events were more likely to have parents or carers concerned about their behaviour $(P<0.001)$ and to have a history of ear $(P<0.001)$ or skin $(P=$ 0.003 ) infections (Box 3 ).

\section{Discussion}

About half of the children in this study had ever experienced stressful events. Strong associations were seen between stressful events and a history of ear and skin infections, and paren- tal or carer concerns about the child's behaviour. No significant differences were seen in the reported exposure to stressful events by individual or familial characteristics.

Compared with the urban Aboriginal and Torres Strait Islander children included in the NATSISS and the WAACHS, our study found a lower rate of stressful events and the absence of some expected stressors. ${ }^{11,12}$ None of our participants reported racism, trouble with the police or unemployment as stressors, whereas $12 \%, 16 \%$ and $32 \%$ of NATSISS respondents, respectively, reported these. In our study, $65 \%$ of parents or carers were unemployed, compared with a background unemployment rate for Aboriginal and Torres Strait Islander adults living in Inala of $24 \%$ in 2006, and rates of $11 \%$ in the broader population of Inala and $4 \%$ across Brisbane. ${ }^{17}$ It is possible that the common experience of unemployment has resulted in it becoming normalised in this group and therefore not considered stressful. However, it may also be an underlying but unacknowledged or unrecognised cause of other stressors such as familial conflict, illness or housing insecurity.

Our study has both strengths and limitations. We used routinely collected clinical data from children attending the health service, thus minimising inconvenience for study participants. Our 344 participants represented $64 \%$ of children having $\mathrm{CHCs}$ at the IIHS in the study period, and $40 \%$ of active patients aged $\leqslant 14$ years. Issues such as the sickness of the presenting child or time constraints of the parent, carer or clinic staff could affect the number of $\mathrm{CHCs}$ conducted. Nonetheless, despite our clinic population comprising only $0.8 \%$ of Australia's urban Indigenous children, our service completed 10\% of the CHCs done in Australian metropolitan areas to June 2009. ${ }^{15}$

Our open-ended enquiry about types and frequency of stressful events introduces the potential for recall bias and underreporting. However, such enquiry is likely to elicit events that were particularly notable for the child and family. ${ }^{18}$ The openended nature of the enquiry also precluded assessment of a doseresponse relationship between exposure and outcomes, and the crosssectional nature of the data prevented any determination of causality between exposure and outcomes. The lack of a time frame associated with the reported stressful events also prevents establishing a temporal relationship between exposure and outcome.

Finally, this study represents one urban Indigenous context and may not be generalisable to other urban areas or Indigenous primary health care services, although there is little reason to assume there would be substantial differences in the results. ${ }^{19}$ These limitations do not negate the seriousness of our findings that about half the children were reported to have been affected by stressful events, and the significant association of this with poorer physical health and parental concerns about behaviour.

As childhood exposure to stress affects future health and wellbeing, longitudinal research is necessary to disentangle the causes and effects of 
stressful events. Health care services need to respond to any disclosure of stressful events by providing access to appropriate medical, psychological or social interventions, preferably through "in house" health professionals or referral to culturally competent community agencies. However, simply treating the impact of stressful events is insufficient without also dealing with the colonial legacy of displacement, child removal, marginalisation and exploitation that contributes to the excessive rates of transgenerational trauma and socioeconomic disadvantage experienced by Aboriginal and Torres Strait Islander peoples. ${ }^{9,20}$ The risk of not addressing both the causes and the effects of childhood exposure to stressful events is that the disparity in life expectancy between Indigenous and non-Indigenous Australians is unlikely to improve. ${ }^{8,9}$

Competing interests: Deborah Askew and Geoffrey Spurling both currently work at the Inala Indigenous Health Service, and Chelsea Bond is a previous employee.

Received 23 Nov 2012, accepted 21 May 2013.

1 Marmot M. Fair society, healthy lives: the Marmot review. London: University College London, 2010. http://www.instituteofhealthequity.org/projects/ fair-society-healthy-lives-the-marmot-review (accessed May 2013).

2 Shonkoff JP, Garner AS. The lifelong effects of early childhood adversity and toxic stress. Pediatrics 2012; 129: e232-e246.

3 Seery MD, Holman EA, Silver RC. Whatever does not kill us: cumulative lifetime adversity, vulnerability, and resilience. J Pers Soc Psychol 2010; 99: 1025-1041.

4 Tosevski DL, Milovancevic MP. Stressful life events and physical health. Curr Opin Psychiatry 2006; 19: 184-189.

5 Wegman HL, Stetler C. A meta-analytic review of the effects of childhood abuse on medical outcomes in adulthood. Psychosom Med 2009; 71 : 805-812.

6 Australian Institute of Health and Welfare. The health and welfare of Australia's Aboriginal and Torres Strait Islander people: an overview 2011. Canberra: AlHW, 2011. (AlHW Cat. No. IHW 42.) http://www.aihw.gov.au/publication-detail/?id= 10737418989 (accessed Mar 2012).

7 Geronimus AT, Hicken M, Keene D, Bound J. "Weathering" and age patterns of allostatic load scores among blacks and whites in the United States. Am J Public Health 2006; 96: 826-833.

8 Nadew GT. Exposure to traumatic events, prevalence of posttraumatic stress disorder and alcohol abuse in Aboriginal communities. Rural Remote Health 2012; 12: 1667.

9 Atkinson J. Trauma trails, recreating song lines: the transgenerational effects of trauma in Indigenous Australia. Melbourne: Spinifex Press, 2002.

10 Australian Bureau of Statistics. General social survey: summary results, Australia, 2010. Canberra: ABS, 2011. (ABS Cat. No. 4159.0.) http:// www.abs.gov.au/ausstats/abs@.nst/mf/4159.0 (accessed Oct 2011).

11 Australian Bureau of Statistics. Social and emotional wellbeing. In: The health and welfare of Australia's Aboriginal and Torres Strait Islander peoples, Oct 2010. Canberra: ABS, 2011. (ABS Cat. No. 4704.0.) http://www.abs.gov.au/AUSSTATS/ abs@.nsf/lookup/32EA68BE4FCA987BCA257 $839000 F A 950$ (accessed Mar 2011).

12 Zubrick SR, Silburn SR, Lawrence DM, et al. The Western Australian Aboriginal Child Health Survey: the social and emotional wellbeing of Aboriginal children and young people. Perth: Curtin University of Technology and Telethon Institute for Child Health Research, 2005. http:// aboriginal.childhealthresearch.org.au/kulunga- research-network/waachs/waachs-volume2.aspx (accessed May 2013).

13 Eades SJ, Taylor B, Bailey S, et al. The health of urban Aboriginal people: insufficient data to close the gap. Med J Aust 2010; 193: 521-524.

14 Priest N, Mackean T, Waters E, et al. Indigenous child health research: a critical analysis of Australian studies. Aust N Z J Public Health 2009; 33: $55-63$

15 Coleman JJ, Spurling GK, Askew DA, Hayman NE. Indigenous child health checks: the view from the city. Med J Aust 2011; 194: 535-536.

16 Hayman NE, White NE, Spurling GK. Improving Indigenous patients' access to mainstream health services: the Inala experience. Med J Aust 2009; 190: 604-606.

17 Australian Bureau of Statistics. 2006 Census tables: Inala (statistical local area). Census Table 20680 - Age by Indigenous status by sex - Inala (ABS Cat. No. 2068.0.) Canberra: ABS, 2007. http:/ /www.censusdata.abs.gov.au/ABS Navigation/ prenav/ViewData?action $=404 \&$ documentproductno=305071288\&document type=Details\&order $=1 \&$ tabname $=$ Details\&area code $=305071288 \&$ issue $=2006 \&$ product type $=$ Census\%20Tables\&javascript=false \&text version $=$ false $\&$ navmapdisplayed $=$ true $\&$ breadcrumb=TLPD\&\&collection=Census\&period $=2006 \&$ productlabel $=$ Age $\% 20$ by $\% 20$ Indigenous\%20Status\%20by\%20Sex\&product ype $=$ Census $\% 20 T a b l e s \&$ method $=$ Place $\% 20$ of\%20Usual\%20Residence\& (accessed Feb 2012).

18 Friborg 0 , Rosenvinge JH. A comparison of openended and closed questions in the prediction of mental health. Qual Quant 2013; 47: 1397-1411. do: 10.1007/s11135-011-9597-8.

19 Rothman K, Greenland S. Modern epidemiology. 2nd ed. Philadelphia: Lippincott Williams \& Wilkins, 1998.

20 Wethington HR, Hahn RA, Fuqua-Whitley DS, et al. The effectiveness of interventions to reduce psychological harm from traumatic events among children and adolescents: a systematic review. Am J Prev Med 2008; 35: 287-313. 